\title{
Postmarketing surveillance: practical experience with ketotifen
}

\author{
WILLIAM P MACLAY, DAVID CROWDER, STEPHEN SPIRO, PAUL TURNER
}

\begin{abstract}
In a postmarketing surveillance of ketotifen (Zaditen), an oral preparation for the prophylaxis of bronchial asthma, 8291 patients completed records every three months for one year. The objectives were to record adverse events and efficacy and to communicate appropriate information to participating doctors and regulatory authorities. The patients recruited appeared to represent a typical cross section of patients with asthma in the United Kingdom. By subjective assessment $\mathbf{7 0} \%$ of patients found the medication efficacious. There were no unexpected or unacceptable side effects and those found were similar to those reported in clinical trials of ketotifen.

Though this exercise showed that the pharmaceutical industry, regulatory authorities, and prescribing doctors were able to collaborate, the major outcome of the survey was already known. It remains to be seen whether this type of survey is of value in the continuing search for control and safety in prescribing.
\end{abstract}

Sandoz Products Ltd, Feltham, Middlesex TW13 4EP WILLIAM P MACLAY, MB, medical director

DAVID CROWDER, PHD, MPS, clinical research manager

Brompton and University College Hospitals, London STEPHEN SPIRO, MD, FRCP, consultant physician

St Bartholomew's Hospital, London

PAUL TURNER, MD, FRCP, professor of clinical pharmacology

Correspondence to: Dr William P Maclay, Sandoz Products Ltd, 98 The Centre, Feltham, Middlesex TW 13 4EP.

\section{Introduction}

Postmarketing surveillance may be defined as surveillance of all postmarketing events. Its precise objectives should include identification of problems, validation of cases, measurement of risks of treatment, assessment of these risks in the light of benefits, and communication of appropriate information to prescribers. ${ }^{1}$ Various schemes have been suggested, including registered release ${ }^{2}$; recorded release ${ }^{3} ;$ monitored release ${ }^{4} ;$ and postmarketing surveillance of adverse reactions to new medicines, ${ }^{5}$ but these have not been tried in clinical practice. In 1979 Sandoz began a postmarketing surveillance of a new drug-ketotifen (Zaditen), an oral preparation for the treatment of bronchial asthma.

The objective of this prospective cohort study was to identify 10000 patients treated with ketotifen for one year and record, firstly, adverse events occurring with an incidence of one in 1000; and, secondly, efficacy of the drug in treating asthma, and then to communicate this information to prescribers.

\section{Methods and patients}

General practitioners and hospital doctors were recruited by company medical information executives and hospital liaison officers after ketotifen had been detailed to them but only when the doctor had agreed to prescribe. The doctor was asked to participate in the postmarketing surveillance project and completed a form of agreement. Completed forms were returned to the medical department of Sandoz and the data were entered on to a computer (Geisco Mark III service). The only patient identification entered into the computer was their unique number.

The patient history form recorded age, weight, and sex, and the doctor was asked to classify each patient by type of asthma, result of skin test, history of status asthmaticus, and whether asthma had started during or after childhood. He was also asked to note the severity of the patient's asthma based on his clinical assessment. Concomitant medication was recorded in case of possible drug 
interactions. The presence of any other disease and the smoking history were noted.

With this registration form there were four record forms to be completed at three, six, nine, and 12 months during treatment with ketotifen. These forms were identical and asked for dosage of ketotifen and other antiasthma drugs, a record of adverse events, and the patient's subjective opinion on the efficacy of the drug. The doctor was asked to record all medical events in the previous three months and to give information on whether they were mild or trivial, moderate or troublesome, or severe (where patient or doctor stopped treatment with ketotifen).

The doctor was asked to assess the relation of these events to treatment with ketotifen on a scale of $1-4 \quad(1=$ definitely related; $2=$ probably related; $3=$ possibly related; 4 =probably unrelated). Doctors were also advised to complete the yellow cards for the adverse reactions subcommittee of the Committee on Safety of Medicines for any medical events that occurred during postmarketing surveillance, and they were reminded that if the patient did not complete three months' treatment the form should still be completed for any adverse events and returned.

Doctors completed five forms throughout the $y \in a r$, including the registration data, and were paid a fee of $£ 6$ a form.

\section{Results}

When analysis was started 19252 completed record forms for three months' treatment had been received, and 8291 for 12 months' treatment. A total of $\mathbf{8 9 5}$ patient history forms were received with no follow up treatment records.

\section{AGE DISTRIBUTION}

The average age for all patients in the study was 42 years and for children under the age of 12 the average age was 8 years. Thirty six per cent of the patients were over the age of 50 years. Figure 1 shows the distribution of types of asthma by age and shows the classic picture of cases of extrinsic asthma falling to $28 \%$ at the age of 70 years and of intrinsic asthma rising to $65 \%$ at the same age, the crossover age being about 52 years.

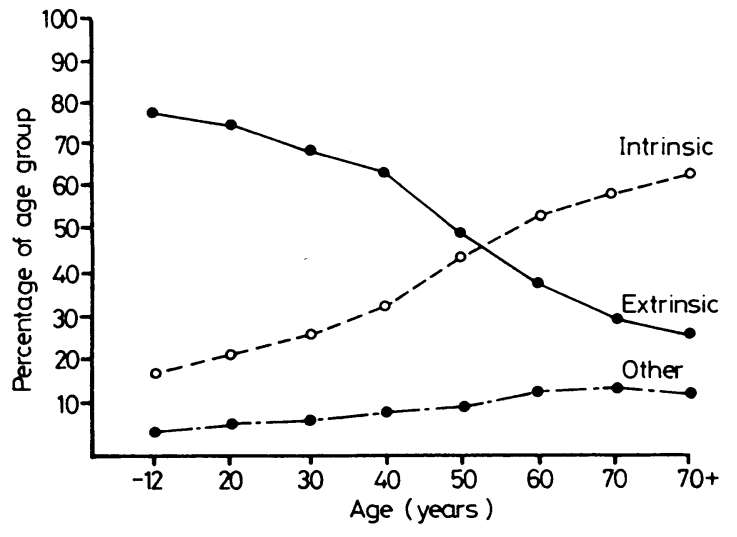

FIG 1-Distribution of types of asthma by age.

Table I gives general information on patients and shows the percentage who completed treatment for 12 months. About a third of all patients gave a history of status asthmaticus and a little more than a third a history of childhood asthma. A quarter of these sufferers from asthma currently smoke.

\section{TYPE OF ASTHMA}

The definition of the aetiological type of asthma was left to the individual doctor. Of those patients classified as having extrinsic asthma $53 \%$ reported onset in childhood compared with $26 \%$ of those classified as having intrinsic asthma, while $23 \%$ of patients with extrinsic asthma and $27 \%$ of patients with intrinsic asthma had a severe form. The percentage of smokers among patients with intrinsic asthma was $28 \%$ and among patients with extrinsic asthma $21 \%$. The differences between male and female subjects showed the recognised ratio of $2: 1$ in favour of boys under the age of 12 years but above the age of 20 years the percentages were similar.

\section{ADVERSE EVENTS}

Table II shows the percentage incidence of adverse events over 12 months, with an incidence of $27 \%$ at three months and $7 \%$ at 12 months. Table III shows the percentage incidence of most frequent adverse events for all patients from three to 12 months. There

\begin{tabular}{lrr} 
TABLE I-Complete records at 12 months in & 8291 \\
patients & & \\
\hline & No & $\%$ \\
\hline Type of asthma: & 4370 & 53 \\
$\begin{array}{l}\text { Extrinsic } \\
\text { Intrinsic }\end{array}$ & 3261 & 39 \\
Other & 660 & 8 \\
Mild & 1137 & 14 \\
Moderate & 5181 & 62 \\
Severe & 1973 & 24 \\
History of status asthmaticus: & & \\
$\quad$ Yes & 2915 & 35 \\
$\quad$ No & 5376 & 65 \\
Asthma started during childhood: & & \\
$\quad$ Yes & 3182 & 38 \\
$\quad$ No & 5109 & 62 \\
Smoking habit: & & \\
Smokers & 2222 & 27 \\
$\quad$ Non-smokers & 6069 & 73 \\
Concomitant diseases: & & \\
$\quad$ Present & 3250 & 39 \\
Absent & 5041 & 61 \\
\hline
\end{tabular}

TABLE II-Adverse events and efficacy in all patients. Figures are percentages

\begin{tabular}{|c|c|c|c|c|c|c|c|c|}
\hline & \multicolumn{4}{|c|}{ Incidence of adverse events } & \multicolumn{4}{|c|}{ Efficacy } \\
\hline & \multicolumn{4}{|c|}{ Months } & \multicolumn{4}{|c|}{ Months } \\
\hline & $0-3$ & 3-6 & $6-9$ & $9-12$ & $0-3$ & $3-6$ & $6-9$ & $9-12$ \\
\hline $\begin{array}{l}\text { All } \\
0-11 \text { years } \\
12-20 \text { years } \\
21-30 \text { years } \\
31-40 \text { years } \\
41-50 \text { years } \\
51-60 \text { years } \\
61-70 \text { years } \\
70+\text { years }\end{array}$ & $\begin{array}{l}27 \\
13 \\
22 \\
27 \\
29 \\
30 \\
29 \\
27 \\
27\end{array}$ & $\begin{array}{r}12 \\
7 \\
9 \\
11 \\
13 \\
14 \\
14 \\
12 \\
11\end{array}$ & $\begin{array}{r}9 \\
6 \\
7 \\
8 \\
8 \\
10 \\
10 \\
8 \\
11\end{array}$ & $\begin{array}{l}7 \\
5 \\
6 \\
6 \\
7 \\
8 \\
8 \\
6 \\
7\end{array}$ & $\begin{array}{l}76 \\
85 \\
81 \\
77 \\
76 \\
74 \\
74 \\
75 \\
74\end{array}$ & $\begin{array}{l}89 \\
92 \\
92 \\
90 \\
90 \\
89 \\
80 \\
98 \\
89\end{array}$ & $\begin{array}{l}93 \\
92 \\
96 \\
94 \\
94 \\
92 \\
91 \\
93 \\
91\end{array}$ & $\begin{array}{l}94 \\
93 \\
94 \\
95 \\
95 \\
93 \\
92 \\
94 \\
92\end{array}$ \\
\hline
\end{tabular}

TABLE III-Commonest adverse events (percentage incidence) in all patients

\begin{tabular}{|c|c|c|c|c|}
\hline $\begin{array}{r}\text { Months } \\
\text { No of patients }\end{array}$ & $\begin{array}{r}3 \\
19252\end{array}$ & $\begin{array}{r}6 \\
12842\end{array}$ & $\begin{array}{r}9 \\
9961\end{array}$ & $\begin{array}{r}12 \\
8291\end{array}$ \\
\hline $\begin{array}{l}\text { Sedation } \\
\text { Dizziness } \\
\text { Nausea } \\
\text { Headache } \\
\text { Dry mouth } \\
\text { Weight gain } \\
\text { Asthma worse } \\
\text { Bronchospasm } \\
\text { Status asthmaticus }\end{array}$ & $\begin{array}{r}14 \cdot 1 \\
1.8 \\
1.2 \\
1 \cdot 1 \\
1.2 \\
0.9 \\
1.4 \\
1.2 \\
0.6\end{array}$ & $\begin{array}{l}4 \cdot 7 \\
0 \cdot 6 \\
0 \cdot 4 \\
0 \cdot 5 \\
0 \cdot 6 \\
0 \cdot 7 \\
0 \cdot 2 \\
0 \cdot 7 \\
0 \cdot 2\end{array}$ & $\begin{array}{l}2.7 \\
0.5 \\
0.7 \\
0.5 \\
0.4 \\
0.5 \\
0.1 \\
0.8 \\
0.1\end{array}$ & $\begin{array}{l}2 \cdot 2 \\
0.3 \\
0.3 \\
0.3 \\
0.5 \\
0.4 \\
0 \cdot 0 \\
0.6 \\
0.1\end{array}$ \\
\hline
\end{tabular}

was little difference in the incidence of adverse events whether the patients had mild, moderate, or severe asthma, or between patients with different types of asthma.

The data on adverse events included 195 separate conditions at three months and 107 conditions at 12 months. In all a total of 244 different conditions were volunteered.

Table IV shows the 18 most frequent adverse events with an incidence of one in 1000 and which were either moderate or severe. Sedation, tiredness, weight gain, and dry mouth were the most common, extending over the 12 months. 
There were 49 deaths resulting from myocardial infarction giving an incidence of $0.25 \%$. The expected incidence of death from myocardial infarction is $0.21 \%$ (based on the 1982 total of 105413 deaths in the population of England and Wales of 49011000 ).

There were 18 deaths resulting from bronchopneumonia, 15 from cancer, and 11 from asthma. Other causes of death included cor pulmonale, pulmonary embolus, congestive cardiac failure, and gastrointestinal haemorrhage. The incidence of death from asthma in this study was $0.05 \%$, whereas in the million patients with asthma in the United Kingdom the incidence of death from asthma is $0.15 \%$.

TABLE IV-Definitely related and probably related (moderate to severe) adverse events (incidence of 1 in 1000)

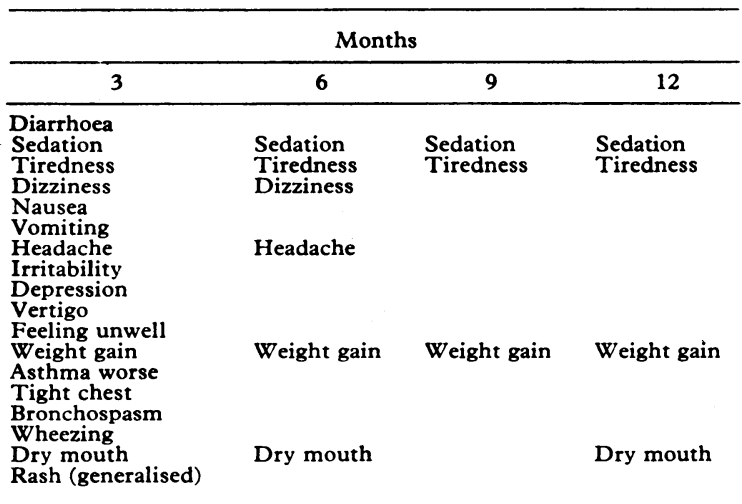

Deaths occurred at a consistent rate of approximately $0.25 \%$ between each three month reporting period, and the total number of deaths in the study was 126 . There were no trends that showed increasing incidence of deaths through each three month reporting period, and no deaths were attributed to the drug.

There were 17 cases of non-fatal myocardial infarction-five in the first three months, and two, eight, and two in each subsequent three month period. Other serious events included 19 cases of pneumonia, 11 cases of congestive cardiac failure, and three cases of jaundice.

\section{EFFICACY}

A subjective opinion of efficacy was made by the patients, $76 \%$ reporting efficacy after three months (table II). It was not surprising that those patients who completed 12 months' treatment reported $93 \%$ efficacy, because most non-responders had discontinued treatment, and dropouts from adverse events had been excluded. Over the 12 months there were changes in the number of other drugs prescribed for asthma, and of those patients who had completed the 12 months $4897(59 \%)$ were able to decrease other drugs compared with $458(5 \%)$ who increased other drugs. This was more apparent in the younger age groups where $66 \%$ under the age of 11 were able to reduce concomitant medication compared with $49 \%$ over the age of 70 years. In addition, children reported greater benefit with fewer adverse events.

In examination of the total sample, it was apparent from the three months total of 19252 compared with the six months total that $33 \%$ of patients did not return, and fig 2 shows the dropout rate throughou the 12 months. The total number of patients who did not return is divided into two groups: "explained" drop outs were the patients who had said they would stop the drug (5218), and "unexplained" were those who had said they would continue (5743). Of the explained losses to follow up, $81 \%$ reported lack of efficacy with or without adverse events. Of the unexplained losses $93 \%$ reported that the drug was effective at the last visit.

\begin{tabular}{|c|c|c|c|c|c|c|}
\hline 3 months & $\longrightarrow$ & 6 months & $\longleftrightarrow$ & 9 months & $\longrightarrow$ & 12 months \\
\hline 19252 & $\begin{array}{l}33 \% \\
\text { lost }\end{array}$ & 12842 & $\begin{array}{l}24 \% \\
\text { lost }\end{array}$ & 9961 & $\begin{array}{l}19 \% \\
\text { lost }\end{array}$ & 8291 \\
\hline
\end{tabular}

FIG 2-Dropout rate of patients over the 12 month study period showing percentage lost to follow up between each three months' assessment.

\section{OTHER INFORMATION}

Forty healthy babies were delivered to women who took ketotifen at some time during their pregnancy after this study had started. The patients took the drug for varying periods, seven patients continuing throughout pregnancy. The only abnormalities reported were three cases of neonatal jaundice, which resolved without problems, and one case of low birth weight probably "because the mother smoked." Of the seven patients who took ketotifen throughout pregnancy the only problems reported were two premature births, at 35 and 36 weeks.

\section{Discussion}

The objectives of this postmarketing surveillance were to identify the incidence of drug related events, to assess subjective efficacy, and to alert prescribing doctors to any important side effect that might become apparent only from a study of this size.

The intention of the study was to follow 10000 patients for one year; however, this required a much larger initial recruitment. We recruited 19252 patients and still managed to follow up only 8291 patients for a full year. Despite 10000 doctors agreeing to contribute five patients each $(50000)$ only 4500 doctors sent in at least one set of completed records. This study cost $£ 250000$ in payments to doctors for patients completing the study year alone, leaving aside incomplete cases, computing costs, etc. The main conclusion of the postmarketing surveillance was already known-that is, that the drug is sedative. ${ }^{6}$ The costs and efforts such a study entails must, ther'fore, be critically assessed.

In addition to confirming the incidence of the commonest and expected side effect of ketotifen, the results of this survey yielded important additional information. Of prime importance, no other major side effect was recorded other than weight gain, which was a consistent feature throughout the study year (table IV). The drug did not increase the incidence of common serious disorders such as myocardial infarction and pneumonia, but a study even of this size is not sufficiently large to exclude an increased association with rarer disorders-for example, pancreatitis-but this seems unlikely.

Another benefit of this postmarketing surveillance was that the information obtained caused two changes in the ketotifen data sheet-the first giving a clearer warning of the likelihood and incidence of early sedation, and the second stating that ketotifen treatment should be established for at least two weeks before attempting reduction of concomitant medication.

Efficacy, interactions, and serendipitous information can be of value, especially in this study where pregnancies provided additional useful data. Many questions are asked by prescribing doctors on the problem of pregnancy and concomitant use of any drug. It is comforting that some assurances can now be given for ketotifen as a result of this study.

An unexpected situation arose when it was discovered that many children under the age of 12 years were given ketotifen, though the data sheet did not advise it at that time. This information on children was gathered, however, and subsequently used as registration data, both in this and other countries.

While others have recorded only suspected adverse effects, we considered it of more value to record all events. ${ }^{7}$ This in itself, however, created difficulties of interpretation. During the trial 195 separate adverse events were recorded at three months and 107 at one year. In all there were 244 different conditions, most of which were likely to be coincidental rather than an effect of the trial drug. Reidenberg and Lowenthal asked healthy university students and hospital staff, taking no drugs, to complete a questionnaire assessing "daily" symptoms. ${ }^{8}$ In the 414 subjects "adverse non-drug reactions" were commonly reported and included excessive sleepiness, fatigue, inability to concentrate, irritability, dry mouth, dizziness, headache, and bleeding gums. 
The assessment of efficacy was simple and relied on the patient's own assessment. This was clearly open to bias but it was considered essential to include some assessment of efficacy so that the relation of risk to benefit could be established. ${ }^{3}$ It did appear from the data obtained that ketotifen was an effective medication, particularly in younger patients, allowing a reduction of concomitant medication in the majority.

When this postmarketing surveillance started in 1979 no similar studies were available with control data. A control group was not included because of logistic problems and the difficulty in identifying a comparable control population. For example, a recent study used case notes selected from files of general practitioners as a control group. ${ }^{9}$ Though these were matched for age and sex they were not matched for disease. Although our study was not controlled it is probable that the 19252 patients entered into this postmarketing surveillance were generally representative of patients with asthma in the United Kingdom with an incidence of extrinsic and intrinsic asthma and age distribution similar to other large surveys. ${ }^{10}$

Analysis of the 895 patients who did not return for the first follow up visit at three months showed that as regards age distribution, diagnosis, etc, they closely resembled the 19252 patients who were analysed. Patients who dropped out of the study and did not attend for their subsequent three monthly visit to the general practitioner were not followed up. While this would have involved considerable further expense it does leave the data open to some criticism regarding the absolute incidence of side effects and efficacy. It is not possible to state with certainty how this additional information would have affected the overall conclusion of the postmarketing surveillance.

Although it has been shown that the pharmaceutical industry, regulatory authorities, and prescribing doctors can collaborate to achieve common objectives it is clear that the major outcome of this survey was already known. Because ketotifen is a safe drug there were no major new adverse events detected. This, however, should not make a study of this type less valuable as it may be of help for others designing similar studies. It remains to be seen whether this expensive type of surveillance is of value in the continuing search for control and safety in prescribing.

We thank Mr R Beasley of Geisco for creating the computer programs; Mrs F Winter for countless hours entering the data; Mrs J Spiers for typing the manuscript; and the many doctors who took part in the study.

\section{References}

1 Inman WHW. Editor's introduction and commentary. In : Inman WHW, ed. Monitoring for drug safety. Lancaster: MTP Press, 1980:6.

${ }^{2}$ Dollery CT, Rawlins MD. Monitoring adverse reactions to drugs. $\mathrm{Br}$ Med f 1977; ; :96-7.

${ }^{3}$ Inman WHW. Recorded release. In: Gross FH, Inman WHW, eds. Drug monitoring. London: Academic Press, 1977:65-78.

${ }^{4}$ Lawson DH, Henry DA. Monitoring adverse reactions to new drugs: "restricted release" or "monitored release" ? Br Med f 1977; i:691-2.

${ }^{5}$ Wilson AB. Post-marketing surveillance of adverse reactions to new medicines. Br Med f 1977; ii:1001-3.

${ }^{6}$ Martin U, Greenwood C, Craps LP, Baggiolini M. Ketotifen. In: Goldberg ME, ed. Pharmacological and biochemical properties of drug substances, vol 3. Washington DC: American Pharmaceutical Association, $1981: 424-60$.

${ }^{7}$ Skegg DCG, Doll R. The case for recording events in clinical trials. $B r M e d$ F 1977;ii: 1523-4.

${ }^{8}$ Reidenberg MM, Lowenthal DT. Adverse nondrug reactions. $N$ Engl $f$ Med 1968;279:678-9.

- Colin-Jones DG, Langman MJS, Lawson DH, Vessey MP. Postmarketing surveillance of the safety of cimetidine: 12 month mortality report. Br Med F 1983;286:1713-6.

${ }^{10}$ Lane DJ, Storr A. Asthma: the facts. Oxford: OUP, 1970:80.

(Accepted 8 December 1983)
$A$ man had a severe attack of shingles with disseminated chickenpox while being treated for Hodgkin's disease. He is now in clinical remission. What risk, if any, would he be under if he came into close contact with a child with chickenpox? If there is a risk what action would be recommended?

Patients with Hodgkin's disease are immunosuppressed. This particularly affects cell mediated immune (CMI) responses. Treatment with cytotoxic drugs may cause further deterioration in immune function. Shingles results from endogenous reactivation of latent varicella/zoster virus, and this is common in such patients. The fact that in addition to shingles this patient also developed varicella suggests that immunosuppression was profound, the disease and its treatment also affecting humoral antibody responses severely; the presence of varicella/zoster antibody would have prevented dissemination of the virus. The patient's severe infection may well have resulted in an antigenic stimulus large enough to provide the patient, now in remission, with a satisfactory humoral antibody response. This would prevent varicella after exposure to a child with chickenpox. The patient's serum, however, could really be tested to determine whether varicella/zoster antibodies were present as a result of his recent infection. Further episodes of shingles may occur and should be promptly treated with acyclovir to reduce the hazard of local or systemic spread.-J E BANATVALA, professor of clinical virology, London.

What protective measures, if any, should be taken in a household containing young children who have cats, dogs, and birds as pets?

Pets of all types provide interesting, educational, and generally hazard free companions for children. It is essential to purchase pets from a reputable source and to treat them for intestinal and external parasites, also taking any preventive measures (especially with dogs and cats) for the common infectious diseases. Such routine medication in cats and dogs, especially those allowed to wander, should then provide trouble free pets for most ages of children. If the pets become ill separate them from children and seek advice from a veterinary surgeon. Take special care with dog bites and deep cat scratches, avoid contact with animal faeces, and be on the constant lookout for the development of any allergic reaction in the children resulting from contact with pets. Birds present a simpler picture in that children will have less contact with them. Again, buy from a reputable source, isolate the bird if sick, and endeavour to keep the children away from the droppings. Some local authorities are unhappy with poultry being kept as pets as they may attract rats.-JOHN R WALTON, senior lecturer in veterinary medicine, Liverpool.

A 40 year old woman has osteoarthritis of her right hip after Perthes disease in childhood. An $x$ ray film of the hip shows severe osteoarthritis and a large cyst in the roof of the acetabulum. A total hip replacement is awaited because of severity of pain and immobility. What should be done about the large cyst?

Subchondral bone cysts are one of the hallmarks of osteoarthritis of the hip. In a 40 year old woman without severe osteoarthritic changes curettage and bone grafting of the cyst might be preferable to joint replacement. ${ }^{1}$ If, however, because of severe osteoarthritis joint replacement is judged to be necessary the cyst in the acetabular roof should be cleared of all debris and fibrous tissue and the acetabular prosthesis then cemented in place in the usual way. If this cyst is very large cancellous bone may be taken from the excised femoral head and packed into the cavity before the prosthesis is inserted. Cupic described a patient in whom a lytic process developed in the ilium above a cemented acetabular prosthesis as a result of mechanical loosening and caseous erosion. ${ }^{2}$ The cyst was explored and the socket changed. Interestingly, this patient was a 36 year old woman who also suffered from the effects of Perthes disease.-S C GallanNaugr, consultant orthopaedic surgeon, Hastings.

\footnotetext{
${ }^{1}$ McBeath AA, Neidhart DA. Acetabular cyst with communicating ganglion. f Bone foint Surg 1976;58A:267-9. F Bone foint Surg $1976 ; 58 A: 267-9$.
Cupic Z. Long-term follow up of Charnley arthroplasty of the hip. Clin Orthop
$1979 ; 141: 28-43$.
} 